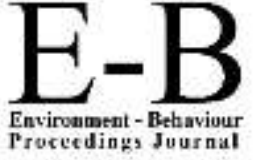

AicE-Bs2018Sheffield

http://www.amerabra.org; $h$ ttps://fspu.uitm.edu.my/cebs $8^{\text {h }}$ Asia-Pacific International Conference on Environment-Behaviour Studies The University of Sheffield, UK. 14-15 July 2018

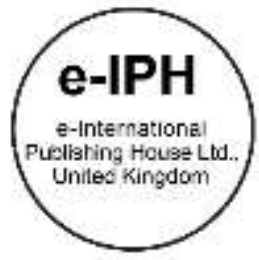

\title{
International Transportation Network Companies: Behaviour of drivers and consumers
}

\author{
Herwina Rosnan ${ }^{1}$, Nuraisyah Chua Abdullah² \\ ${ }^{1}$ Arshad Ayub Graduate Business School \\ 2 Faculty of Law, \\ Universiti Teknologi MARA, 40450 Shah Alam Selangor, Malaysia \\ herwinaros@gmail.com, nuraisyahc@yahoo.com,nuraisyah@salam.uitm.edu.my \\ Tel: +60192345680
}

\begin{abstract}
The growth of Transportation Network Companies (TNCs) in Malaysia is an evidence that their e-hailing services are well-accepted by consumers. The emergent of TNCs which is termed as industry's "disruptive innovation" has changed the traditional way of commuting. This paper seeks to investigate how the recent business environment affects the quality of life and the behaviour of the drivers and consumers at large. The study employs a qualitative content analysis and data was collected from secondary sources. Behaviours of drivers and consumers which contributes to the change of the industry is critical for the policy-maker to respond and introduce appropriate policy.
\end{abstract}

Keywords: Transportation Network Companies; E-hailing; Drivers' Behaviour, Consumers' Behaviour

eISSN: 2398-4287 @ 2018. The Authors. Published for AMER ABRA cE-Bs by e-International Publishing House, Ltd., UK. This is an open access article under the CC BYNC-ND license (http://creativecommons.org/licenses/by-nc-nd/4.0). Peer-review under responsibility of AMER (Association of Malaysian Environment-Behaviour Researchers), ABRA (Association of Behavioural Researchers on Asians) and cE-Bs (Centre for Environment-Behaviour Studies), Faculty of Architecture, Planning \& Surveying, Universiti Teknologi MARA, Malaysia.

DOI: https://doi.org/10.21834/e-bpj.v3i8.1409

\subsection{Introduction}

Globally, the emergence of transportation network companies (TNCs) has changed the way people commute. TNCs refer to technologybased companies that keep on developing and advancing taxi-booking mobile application, also known as ride-hailing or e-hailing service provider. Uber, Grab, Lyft, Sidecars are the examples of global TNCs. In many countries, TNCs are the substitute to other mode of public transportation particularly taxi service. In Malaysia, TNCs started to operate in the early 2016 which market was previously dominated by taxi service. Apparently, passengers prefer e-hailing services for their quality of service which include efficiency, convenience, reliability, and attractive fare rates in comparison to the conventional taxi service. Literally, TNCs has disrupted taxi service evidenced by many efforts made by taxi drivers and its association to influence the government to act against TNCs operations.

Companies and industries keep abreast or ahead of technology in order to catch up with modern consumers' demand. Business sustainability is at risk as companies are raced towards creating new products and offerings to be ahead of rivals. Uber is an example of a newcomer and first mover that introduce innovative e-hailing services and able to capture the market instantaneously. Uber and other TNCs introduced a hostile cost-cutting business model that is unmatched to current industry players. Taxi services, in particular, are severely affected by this current trend in public transport industry which forced the industry to revolutionised.

The growth of TNCs businesses in Malaysia is the evidence of high level of acceptance among consumers as it increases the quality of life of the citizens. Grab and Uber are two main players that dominate the local market. However, in recent development the business environment of TNCs has forced TNCs to retreat from Malaysia's market leaving Grab to dominate e-hailing service sector. In addition, the government echoed that TNCs operations will be subjected to the same policy and regulations imposed to taxi operators, where the

eISSN: 2398-4287 @ 2018. The Authors. Published for AMER ABRA cE-Bs by e-International Publishing House, Ltd., UK. This is an open access article under the CC BYNC-ND license (http://creativecommons.org/licenses/by-nc-nd/4.0/. Peer-review under responsibility of AMER (Association of Malaysian Environment-Behaviour Researchers), ABRA (Association of Behavioural Researchers on Asians) and cE-Bs (Centre for Environment-Behaviour Studies), Faculty of Architecture, Planning \& Surveying, Universiti Teknologi MARA, Malaysia.

DOI: https://doi.org/10.21834/e-bpj.v3i8.1409 
response by the drivers are yet to be analysed comprehensively. Market competition has changed the way taxi is operating. Behaviours of drivers and consumers which contributes to the growth, business sustainability and competition within the industry is critical for the policy-maker to respond in order to ensure that any introduction or changes in policy-making must take into consideration the interest of the general public. Hence, the paper seeks to investigate how the recent business environment affects the quality of life and the behaviour of the drivers and consumers at large. Many taxi drivers began to join TNCs, in which the drivers provide both taxi service and e-hailing service depending on the demand from the customers. This paper is a descriptive study and the method used in the data collection was done through secondary data collection and the sources include articles from research journals, non-research articles, newspaper articles and online news. The study employs a qualitative content analysis.

\subsection{Literature Review}

The emergence of transportation network companies (TNCs) has disrupted the public transportation sector worldwide. TNCs came with totally new business model and this led to discussions among writers and researchers more predominantly in 2013 onwards. Many writers focus on the need for the TNCs for example, Nadler in 2014. As opposed to the traditional "brick-and-mortar" companies, TNCs business model through mobile applications create a competitive advantage to companies Lopes (2015). Beginning 2015, researchers begin to explore how the TNCs affect the economy Post (2015).

In Africa Mulligan (2015) found that TNCs further expansion plan would bring benefit to the economic growth as it provides employment and support the entrepreneurial agenda of the SMEs in Africa. Furthermore, TNCs would bring about positive change in Africa's transportation ecosystem. Mulligan (2015) further argued that TNCs services provide a more reliable and safe public transportation mode to passengers. In the case of drivers, TNCs provide an employment opportunity, in that the business model of TNCs create opportunity for small businesses.

The emergence of TNCs has effect on the growth of other industries. As reported by BMI (2016a), TNCs enter into partnership with Tata car sales to enable Tata to increase vehicles sales through the provision of attractive financing. TNCs supports the expansion of domestic-related sectors for example a partnership with Smart e-Money mobile wallets (e-hailing provides cashless service). These example indicates business opportunities brought by TNCs to other local businesses.

Globally TNCs create a new trend of employment where drivers can make additional income to support living cost (Rosenblat, 2016). Indeed, in some countries where employment is scarce, TNCs create employment opportunity for the citizens from various educational background and previous career tracks. The "sharing economy" as it is termed, brings about substantial economic benefits where labor marketplace is being utilized for the higher rate of employment, thus avoiding "underutilized resources", while fostering innovation. The high expenses due to wear and tear of maintain a private car by a consumer is resolved by the TNCs service especially in Sub-Saharan countries where the consumers tend to use used older imported vehicles, for its affordability (BMI 2016b). The concept of "surge pricing" where fares are adjusted based on demands in the TNCs, affect incumbents and the economy (Dholakia 2015). Surge-pricing is an economic concept of supply and demand where passenger's fares is determined by the balance between customers' demand and service supply. In addition, TNCs service eliminate long waiting time for passengers unlike the traditional taxi service.

Other than economy, the researchers also discussed on the ways TNCs affect the people particularly the drivers. When it comes to a discussion on drivers' welfare, many researchers have criticized TNCs business model that is lack of protection of the drivers welfare. This is because TNCs do not regard drivers as employees but merely an independent contractor who are not bind by employment. Chu (2015) argued that TNCs refused to regard drivers as employees to avoid responsibilities in the case of dispute between drivers and passengers.

Theoretically, since fares is determined by supply and demand, TNCs might reduce the number of drivers to ensure fares are favorable to TNCs and fellow drivers. However, this behaviour creates a disadvantage to consumers (MarketLine 2014). Relatively, TNCs services are more favorable than the tradition taxi services as TNCs offers attractive fares to passengers. The act of reducing the availability of drivers may increase the taxi fare price. This is one of the reasons on why certain countries start to look into the legality of TNCs operation in the host country. There was a debate on the issue of regulating TNCs activities and whether TNCs should be subjected to rules and regulations imposed to traditional taxi services. The relevant authority in many countries has started to look into enacting applicable laws and regulations on licensing and other requirements. As TNCs could be a threat to existing taxi service sector, certain countries imposed rules to hamper or prohibit TNCs' operations (Mulligan 2015). For example, in the U.S, through its legal system, the authority has confronted TNCs business model by emphasising that the TNCs drivers are regular employees and the TNCs need to provide protection and other employment benefits to the drivers (Rosenblat 2016).

There is a growing concern over the operations of TNCs on the safety of the passengers. Some writers concern over the effectiveness of the background check made by TNCs to quality a driver. The system for drivers' background check can easily be manipulated by drivers. For example, others can easily use the identity of registered drivers to provide the service, or a registered driver can easily pass his/her identity for others to do e-hailing. This possibility creates concern over the safety of the passengers (MarketLine, 2014). Further to the discussion, Marketline also exposes the alleged rape case in India where a female passenger was allegedly raped by TNCs driver which resulted in the prohibition of TNCs operations by the local authority. However, Mulligan (2015) disagrees with Marketline by arguing that the new security measures are comprehensive which include drivers' record verification by local police, emergency response team and location function embedded in the applications used by the passengers are considered sufficient to guarantee the safety of the passengers.

In general, many writers agree that benefits from TNCs operations in local market outweigh the drawbacks as TNCs are relatively more efficient than traditional taxi service (O'Byrne, 2016). TNCs services are more favourable due to attractive fares, ease of use, 
reduced waiting time, and transparent services provided through user-friendly mobile applications. However, despite the critics over TNCs operations, Marketline (2014) also reported an increase in drivers registration in the United Kingdom and Ireland market which data shows an increase of 850 per cent compared to the week before. Furthermore, Cramer and Krueger (2016) found that many countries start to support TNCs operation in providing e-hailing service for its efficient service which increases the well-being of the consumers.

On the issue of the impact on TNCs operation on the environment, there are divergent views on whether TNCs operations bring positive effects to the environment. Theoretically, if TNCs services are convenient and more economical, it could reduce car ownership. With the reduced number of cars on the road would lead to cut air pollution and traffic congestion particularly in major cities. However, the impact of TNCs operations on the environment has yet to be supported by previous research.

Further discussion on the impact of TNCs operations on the national economy is from the context of various services provided by TNCs. Marketline also reveals that the activities of TNCs are now beyond passengers but has been expanded to include delivery service which is termed as "logistics fabric", a new creation of innovative modes of transportation delivery. For example, in London, Uber provided kitten delivery service on National Cat Day in 2013, Uber also offer charter-like service known as corporate transportation for corporate businesses and enter into retail ice-cream trucks which are also used to promote Uber brand. While in New York, Uber deliver both packages and e-hailing known as Uber Rush (MarketLine 2014).

A 'sharing economy' is a concept which emphasizes on increasing efficiency and promotes waste reduction, thus achieving sustainability when resources are escalated to attain more efficient markets, an opportunity for income-earning is available. However, Schor (2014) found that the concept of "sharing economy" does not consistent with the empirical evidence on the expansion of TNCs businesses. Marketline (2014) reported that USD1.4 billion fund was raised from investors in around 45 countries as an investment to e-hailing of TNCs operations. Google Ventures, for example, has invested USD258 million in encouraging more people to work with Uber and to support Uber's business expansion which benefits both customers and drivers. Many have seen the benefits brought about TNCs operation that contribute to growing corporate sectors that generate much profits, employment and growth in the economy. TNCs are targeting at a foreign location where economic growth is seen as an opportunity to create a new market and serve new demand in public transportation. Since TNCs are technology-based service, they need to tap into market segments with smartphone penetration, sophisticated network quality, and where the supply of vehicles is growing (Mulligan 2015).

On the legal aspects, TNCs have been accused of manoeuvring domestic regulatory loopholes (Malhotra and Alstyne, 2014). Since the entry barrier is low in this type of business, TNCs generally are enjoying unfair advantages as compared to existing taxi services which is bounded by regulation imposed by the local authority. Due to the nature of the business and the unprecedented business model, it is quite difficult for the local authority to regulate TNCs service as the local authority has to juggle between the cost of regulating and the well-being of the customers who have been enjoying a relatively better service (compared to taxi service). The consequent of this is on the fate of taxi service businesses. Globally, TNCs have become significant threat to taxi drivers.

Nonetheless, Schechner (2013) equates the differences between taxi service operates and TNCs and the findings indicate the burden of licensing of traditional taxis as compared to the status of a driver of TNCs who is merely an independent contractor, rather than employees to the TNCs, hence the writer stressed the significant risks to both passengers and drivers in the event of accidents. Petropoulos in 2016 further reveals that in major cities in the U.S, licensing fee (before Uber's operation) varied between USD350,000 and USD1,000,000, while in Paris licenses cost around 240,000 euros, while Uber conveniently escapes from the licensing rule whilst entering the market. Non-entitlement to minimum wage, health insurance and work-leave as adverse side-effects of TNCs drivers is further commented by Petropoulos (2016). As a result, TNCs can reduce prices due to lower operating costs incurred to their such as administrative and running costs. Ironically, due to its distinctive business model, Uber was reported to be barred in many countries such as Belgium, France, Germany, Italy and Spain. Schechner (2013) revealed that this is as a result of the efforts taken by traditional taxis in lobbying the government to ban the operation of TNCs due to the argument of unequal competing grounds regarding standard waiting time that a customer experienced. Due to the lack of comprehensive discussion on behaviours of consumers and drivers in the TNCs industry, this article aims to fill the gap.

\subsection{Analysis and Discussion}

Many taxi drivers began to join TNCs as a result of consumers' demand who prefer e-hailing service. In its initial establishment, TNCs viewed themselves as technology companies rather than public transport providers. However, many countries argued that although technology is the backbone of their business, as a matter of fact, they are providing transport service. Many taxi drivers in Malaysia have a dual career, i.e. as a taxi driver and e-hailing driver. As a result of taxi driver participation in TNCs, it has generally improved taxi service. This is TNCs drivers are perceived to have better manners and behaviours. This indirectly has changed the behaviours of taxi drivers indirectly as they have to compete with the TNCs drivers. The study indicates consumer preference of e-hailing services over conventional taxi service. However, market competition has changed the way taxi is operating.

Currently in Malaysia, Uber and Grab posed a positive impact to their drivers. In this challenging current economic environment where job opportunities are scarce, coupled with retrenchment and lay-off exercises by many giant corporations, the pressures have forced thousands of Malaysian to become ride-hailing drivers. TNCs also create income opportunity for the citizens to cope with rising cost of living. It was reported that approximately 80 percent of e-hailing drivers in Malaysia are part-timers who are trying to earn additional income to deal with rising cost of living. Majority of the drivers are among the bottom 40 percent category (B40) comprise of students and part-timers. On top of that, in the absence of the middleman, e-hailing drivers receive higher shares of their fares compared to taxi drivers who have to pay rent to the vehicle owner. 
When it comes to security, drivers of e-hailing enjoy a more secure working condition as opposed to taxi drivers. They are less exposed to robbery as they do not carry cash. In addition, they experience greater assurance of safety as passengers are registered, and identities are known within the application. While passenger for street-hailing taxi service is entirely anonymous. However, taxi drivers are negatively impacted by the operation of Uber and Grab as they cannot compete with a new business model introduced by this technology-based companies. This is because the screening of TNCs drivers is more lenient compared to taxi drivers. Such leniency on drivers led to misuse of the system by the drivers. The process of becoming an Uber driver is simple. The applicants just need to submit their name and identification number to TNCs for screening and a background check. There is no requirement to substantiate that the information provided genuinely belongs to the applicant. Theoretically, someone with criminal records can use other people identity to become an Uber driver, or a genuine Uber driver can allow other people to do e-hailing on his or her behalf.

Nevertheless, in Miami, Florida, Uber claimed that they made a thorough background check on the approved drivers. This is done by the engaging private company to use social security number and do the background check against various databases which include national and local databases for a criminal record or any other convictions for the past seven years. In this case, drivers may be disqualified if he or she is found to have criminal records or any road violation which include a total of three minor violations like speeding tickets or minor accidents for the past three years.

Another negative impact on drivers are concerning the drivers' welfare which comes into question as they are not regarded as employees by TNCs. As they are not an employee, TNCs has no responsibilities to protect them in case of accidents or dispute between drivers and passengers. Most TNCs compete over price, this and competition could cause a race to the bottom in which drivers are trapped in extremely price-sensitive consumers. This resulted in suppressed income to drivers.

TNCs are direct competitors for taxi services which have long monopolised the use of private cars as public transport. In general, TNCs provide more affordable and cheaper fares, relatively more reliable, comfortable and convenient for many consumers.

The growth of Uber and Grab in Malaysia is evidence of the efficiencies of their services. Basically, globalisation and free-market bring about competition and competition provide alternative and options for the consumer to choose. Competition gives pressures to companies to provide better service to capture consumers. Hence, competition will ultimately benefit the consumers at large. In the absence of competition, complacency is prevalent, and this is what happened in the taxi industry in Malaysia where taxi drivers and operators are lack of initiatives to improve the quality of their services. What really matters to consumers is the quality of the service they acquire. On whether TNCs are a threat to the local industry is not the concern of the passengers. In addition, TNCs service has become an alternative for passengers as it becomes a substitute for other public transportation like bus or train service. Passengers are able to escape packed public transportation system Bohari, Bachok and Osman (2016).

TNCs like Uber is committed to assuring the safety of the passengers. The applications were developed to increase security to both drivers and passenger. For example, in India Uber's application implement specific security measure which includes the function of "share my ETA", police verification of drivers; record and emergency response team. In brevity, TNCs service has benefited consumers in many ways and increase their well-being as e-hailing passengers deserve their safety to be taken care of while taking a ride (Bohari et al., 2014). Despite few cases involving the safety of passengers of TNCs, many are still optimist that TNCs are better than traditional taxi services.

Using smart technology, a customer is better assured that his welfare and safety is taken care in the ridesharing model of as contrary to conventional taxis. TNCs platform reduces the risk associated with traditional taxi-hailing where taxi driver's identity is anonymous to the passengers. In Malaysia, similar to other countries, the debate over the operation of TNCs has caused different reactions from many quadrants. The local taxi industry has pressured the government to intervene, and incidences on passengers' safety have brought about concern over unregulated TNCs operation. However, to date, after five years in services, neither legal actions nor explicit prohibitions are taken against the drivers of TNCs, despite the unresolved regulatory issue, which may lead to constant dissatisfaction on the part of traditional taxis.

\subsection{Conclusion and Implication}

Many taxi drivers began to join the TNCs and become both the taxi driver and e-hailing driver as they responded to the change of consumers' behaviour and demand. As a result, from the participation of taxi drivers in e-hailing, it has improved the behaviour of taxi drivers (TNCs' drivers relatively have better manners and behaviours), and this led to the change of behaviours of taxi drivers. Indirectly, it improves taxi service and improves taxi operators' reputation. The study indicates consumer preference of e-hailing services over conventional taxi service. However, market competition has changed the way taxi is operating. Behaviours of drivers and consumers which contributes to the growth, business sustainability and competition within the industry are critical for the policy-maker to respond to ensure that any introduction or changes in policy-making must take into consideration the interest of the general public.

\section{Acknowledgements}

The authors would gratefully acknowledge the Institute of Research Management and Innovation (IRMI) Universiti Teknologi MARA (UiTM), Shah Alam and Ministry of Higher Education Malaysia (MOHE) for the financial support through the Fundamental Research Grant Scheme, File No: 600-IRMI/FRGS 55/3(36/2015). 


\section{References}

BMI Ltd 2015a, Americas Automotives Insight - October 2015, BMI, ProQuest database.

BMI Ltd 2015b, Asia Pacific Telecommunications Insight - Nov 2015, BMI, ProQuest database.

BMI Ltd 2016a, Asia Pacific Automotives Insight - Sep 2016, BMI, ProQuest database.

BMI Ltd 2016b, Middle East \& Africa Automotives Insight - October 2016, BMI, ProQuest database.

Bohari, Z. A., Bachok, S., \& Osman, M. M. (2014). Improving the Quality of Public Transportation System: Application of Simulation Model for Passenger Movement. Procedia - Social and Behavioral Sciences, 153, 542-552.

Bohari, Z. A., Bachok, S., \& Osman, M. M. (2016). Simulating the Pedestrian Movement in the Public Transport Infrastructure. Procedia - Social and Behavioral Sciences, 222, 791-799

Bremner, C 2015, 'Uber - Court Cases, Bans and Automobiles', Passport, 4 March, viewed 27 December 2016, Euromonitor International database.

Bremner, C 2015, 'Uber - Court Cases, Bans and Automobiles', Passport, 4 March.

Chase, R 2015, 'Who benefits from the Peer-to-peer economy?', Harvard Business Review.

Chen, L 2015, 'Uber Wants to Conquer the World, But These Companies Are Fighting Back', Forbes, 9 September, <http://www.forbes.com/sites/liyanchen/2015/09/09/uber-wants-to-conquer-the-world-butthese-companies-are-fighting-back-map/\#3827e3f62925>.

Cheney, C 2016, 'What is driving Uber's global impact?', deveximpact, 5 August, viewed 22 December 2016, <https://www.devex.com/news/what-is-driving-uber-s-globalimpact88419>.

Chu, Y 2015, 'Is ride-sharing really as novel as it claims - Understanding Uber and its supply side impacts in New Zealand', Victoria University of Wellington, <http://researcharchive.vuw.ac.nz/xmlui/bitstream/handle/10063/4932/paper.pdf?sequence= 1 >.

Coyle, JJ, Langley Jr., CJ, Novack, RA \& Gibson, BJ 2013, Managing Supply Chains: A Logistics Approach, 9th Edition, South-Western Cengage Learning, Canada.

Cramer, J \& Krueger, AB 2016, 'Disruptive Change in the Taxi Business: The case of Uber', American Economic Review: Papers \& Proceedings, May, vol. 106, no. 5, pp. 177-182.

Dholakia, UM 2015, 'Everyone hates Uber's surge pricing - Here's how to fix it', Harvard Business Review, viewed 27th December 2016, <https://hbr.org/2015/12/everyone-hatesubers-surge-pricing-heres-how-to-fix-it>.

Euromonitor International database.

MarketLine 2014, Uber Technologies Inc.: Calling a cab for the Taxi Industry? Progressive Digital Media Ltd.

Mulligan, G 2015, 'Uber comes to Africa', African Business, February, is. 416, pp. 54-55.

Nadler, D 2014, 'Tesla and Uber Are Driving Clunker Business Models to the Junkyard', Institutional Investor, 9 April, p. Institutional Investor.

NewsRx Health \& Science 2016, 'Tough social issues provide a challenge for companies and researchers', 3 March, pp. 245.

O’Byrne, R 2016, 'The Uberisation of Logistics', MHD Supply Chain Solutions, September/October, Vol. 46, No. 5, pp. 36-38.

Organisation for Economic Co-Operation Development (OECD) \& Eurostat 2014, Oslo Manual: Guidelines for Collecting and Interpreting Innovation Data, 3rd Edition, OECD Publishing, Paris.

Oxford Analytica 2014, 'Taxi apps could change transport models', Oxford Analytica Daily Brief

<https://eprints.worc.ac.uk/3370/1/F_Oxford\%20Analytica\%20Daily\%20Brief\%20\%20Taxi\%20Apps\%20Could\%20Transform\%20Global\%20Transport\%20Models.pdf/

Parigi, P \& State, B 2014, 'Disenchanting the World: The Impact of Technology on Relationships', in LM Aiello \& D McFarland (eds), Social Informatics, Springer International Publishing, New York, pp. 166-182.

Petropoulos, G 2016, 'Uber and the economic impact of sharing economy platforms', Pieria, 26 February, <http://www.pieria.co.uk/articles/uber_and_the_economic_impact_of_sharing_economy_plat forms>.

PwC 2015, The Sharing Economy, PricewaterhouseCoopers, viewed 18 December 2016, <https://www.pwc.com/us/en/technology/publications/assets/pwc-consumerintelligenceseries-the-sharing-economy.pdf>.

PYMNTS 2015, 'Is Technology the Taxi Industry's Lifeline?', PYMNTS, 5 May, <http://www.pymnts.com/in-depth/2015/is-technology-the-taxi-industryslifeline/>.

Rosenblat,A 2016, 'What motivates the Gig Economy Workers', Harvard Business Review, <https://hbr.org/2016/11/what-motivates-gig-economyworkers>.

Schechner, S 2013, 'Corporate News: Uber in French Street Fight --- Online Car-Service Firms to Oppose New Rule as Apps Shake Up Taxi Business', Wall Street Journal, 31 December, p. B.3.

Schor, J 2014, 'Debating the sharing economy', Great Transition Initiative, <http://greattransition.org/publication/debating-the-sharing-economy>. 